\title{
Growth of Astronomical Thought
}

A Hundred Years of Astronomy

By Reginald L. Waterfield. (The Hundred Years Series.) Pp. 526. (London : Gerald Duckworth and Co., Ltd., 1938.) 21s. net.

$\mathrm{M}^{\mathrm{R}}$ . WATERFIELD has undertaken a very heavy task, and has produced an interesting and useful work. There are, especially in the United States, many text-books of 'descriptive' astronomy, with formulæ, diagrams, and (sometimes) excellent illustrations. This is something quite different. Its production has evidently entailed a very considerable amount of research into historical questions, and yet it is not by any means purely a history. The layman will probably feel, after a first reading, that there is an astonishing amount of astronomy of which he had scarcely heard, but which appears, on the whole, to be within his powers of comprehension, and is fascinating in its interest, once it is grasped. For the author has set out to describe not merely the development of knowledge but also the development of understanding; he sketches the processes of thought, the conflicting evidence, the puzzles, and their solution (when it has been attained), and he outlines present knowledge and speculation in a very readable way. Such a question as the motions of the stars as a whole might seem poorly suited to exposition for the lay mind, with no formulæ and practically no technical terms allowed ; but by an apt use of analogies from everyday life, Mr. Waterfield does, in fact, hold the various classes of motion distinct in the reader's mind, and guides him, if he has a reasonably strong determination to follow, through a maze that was largely uncharted even by professionals at the start of the present century.

Mr. Waterfield is an amateur astronomer, and astronomy is pre-eminently the science in which amateurs always have distinguished themselves. On topics that usually interest amateurs most, he may be taken as authoritative; such matters as physical observations of the planets, the behaviour of long-period variables, and the construction of telescopes, may fairly be expected to be competently handled, and in fact dynamical and statistical astronomy are at least as well treated. It must, however, be added that he is less sound on the details of astrophysics, atomic theory, and also fundamental astronomy. The errors are as a rule not of a nature to damage the whole presentation seriously, but they are more numerous than one would wish.

The book also suffers from some defects in arrangement, especially in the earlier chapters. The author describes it himself as "at first sight somewhat chaotic", and it must be said that it does not improve with acquaintance. "Wireless Time Signals and Stellar Evolution" is perplexing as a chapter-heading; so is "Solar Physics and the Motions of the Stars". The arrangement is apparently due to an attempt to group together questions that arose at the same time; but even so the author is not consistent, since "Stellar Evolution" is allowed to run right on to the latest developments in curved space. The later chapters are better in this respect. There are other signs of inadequate revision, but it should perhaps be said that the author can in fact plead that at the time he was seriously hampered by circumstances beyond his control.

Perhaps in a second edition, which it is much to be hoped will be called for, these superficial blemishes may be rectified. The book as a whole is altogether too good to be judged by its defects. R. d'E. A.

\section{Vanishing Tribes of India}

The Travancore Tribes and Castes

By L. A. Krishna Iyer. Vol. 1. Pp. xxi $+277+$ 60 plates. (Trivandrum: Government Press, 1937.) 7 rupees.

$\mathrm{T}^{\mathrm{T}}$ was the ardent wish of that veteran ethnoI logist, L. K. Anantakrishna Iyer, to complete the survey of South India with volumes on Coorg and Travancore. His work in Coorg was cut short by his death, and it is fitting that the Travancore Survey should be entrusted to his son. Wisely the
Travancore Government decided that first attention should be given to the hill tribes, whose social and religious institutions are fast vanishing. Only seven of these tribes are dealt with in this volume, which repeats and amplifies the admirable synopses of the Census Report for 1931, based on the author's notes.

Of the seven tribes, three are assumed to be offshoots of Hinduized communities well known in the plains, the Kuravans, the Pulayans and the Vedans. The Hill Pandarams, who number only 